\title{
THE AUTOMATIC AND THE INCOMPLETE. REMARKS ON RECANATI'S LITERAL MEANING
}

\author{
Stefano Predelli \\ Department of Philosophy \\ University of Nottingham \\ Stefano.predelli@nottingham.ac.uk
}

SUMmARY: In this essay, I focus on Recanati's treatment of 'What is said' in his book Literal Meaning. I discuss Recanati's conception of Minimalism, his views on propositional completeness, and his understanding of the processes governing the semantic interpretation of meaning-controlled contextuality. In the final sections, I draw some conclusions pertaining to Recanati's assessment of the interface between pragmatic and semantic processes.

KEY WORDS: 'what is said', indexicality, semantics, pragmatics

RESUMEN: En este ensayo me enfoco en el trato que le da Recanati a "lo que se dice" en su libro Literal Meaning. Discuto su concepción del minimismo, su posición sobre la completud proposicional y su comprensión de los procesos que rigen la interpretación semántica de la contextualidad controlada por el significado. En las secciones finales, extraigo algunas conclusiones acerca de la evaluación que Recanati hace de la interfase entre procesos semánticos y pragmáticos.

PALABRAS CLAVE: "lo que se dice", indexicalidad, semántica, pragmática

Literal Meaning is a rich and thought-provoking contribution to the current debate on the semantic/pragmatic interface (Recanati 2004). In this essay, I focus on one of the prominent themes in Recanati's book, his assessment of the allegedly well entrenched minimalist and/or literalist standpoints in philosophical semantics. In particular, I discuss Recanati's notions of propositional incompleteness and automatic interpretation, and their relationship to the fundamental idea of meaning-controlled contextuality.

\section{What Is Said and WIS}

One of the central motives in Recanati's discussion is the analysis of a semantic level presumably prior to the rich and uncontroversially pragmatically determined information imparted by an utterance. For instance, in some intuitive and by now well explored sense, an utterance of 'I am French' may impart that the speaker is a good cook on the basis of, among other things, certain processes and regularities responsible for the content that, roughly, the speaker is of a certain nationality. This latter information content is occasionally 
labeled as what is said by the utterance in question, or as the proposition semantically expressed by it, in contrast to the message(s) pragmatically conveyed, such as the notion that he is a good cook. What Recanati is primarily concerned with in Literal Meaning are alternative accounts of what is said, roughly positioned on differing locations along the minimalist vs. contextualist scale. The main target of the book's pars destruens in the first chapters are proposals closer to the minimalist extreme; the second half of Literal Meaning is devoted to Recanati's pars construens, his defense of a radical form of Contextualism.

Both the locution 'what is said' and the everyday notion of what is said are associated with preliminary connotations that may well hinder the neutral assessment of alternative analyses of the semantic level(s) here under discussion. For instance, the expression "what is said' is by now irrevocably linked with the work of Paul Grice on implicature. ${ }^{l}$ Although what is said is there introduced as a preexisting and relatively intuitive notion, it is soon accompanied by a particular and possibly controversial analysis of it, roughly in terms of the contributions provided by lexical meaning, together with a very limited set of contextual considerations. Yet, it is neither the Gricean understanding of 'what is said' nor the everyday take on that notion that are Recanati's initial concern. Whether a suitable semantic role may be found for the construct resulting from conventional meaning + reference assignment + indexical interpretation, and whether this role somehow reflects any pre-theoretic everyday concept, are questions that ought to be the result of the type of inquiry pursued in Literal Meaning, rather than its starting point. It is for this reason that, in my own analysis of Recanati's proposal, I speak in terms of a deliberately artificial notion, whose exact composition and function remain to be addressed: I settle for the acronym WIS (for "What Is Said', with the capitals alluding to the possibly theoretically laden understanding of this idea).

In chapter one of Literal Meaning, WIS is preliminarily identified by the role it is supposed to play within an account of content and communication. One of the boundaries constraining the notion under discussion has to do with conventional meaning (roughly, at least in most of Recanati's book, a notion playing a role similar to that of Kaplan's character). ${ }^{2}$ In particular, it seems clear that, on any account of the processes leading to the association of certain

${ }^{1}$ See Grice 1989.

${ }^{2}$ See Kaplan 1989.

Crítica, vol. 38, no. 112 (abril 2006) 
information contents with utterances of 'I am French', appropriate attention ought to be paid to the arbitrary behavior associated by the rules for English (or, perhaps, for the appropriate idiolect) to the simple expressions 'I', 'am', and 'French', and to the syntactic structure within which they are combined. In Recanati's approach as well as for the traditional standpoint, conventional meaning is prior to WIS, in the sense that WIS is at least in part determined by decisions of meaning: the WIS for Recanati's utterance is at least one of the items whose identity depends on the conventional profile of the appropriate lexical entries and of their compositional union.

The opposite boundary constraining the interpretation of WIS has to do with the aforementioned uncontroversially pragmatic levels of information content, such as those deriving the notion that the speaker is a good cook on the basis of Grice's mechanisms of implicature. Regardless of what exactly it turns out to be, WIS is somehow prior to implicatures, presumably in the sense that the calculation of implicatures must depend, among other factors, upon the identification of the relevant WIS.

For Recanati, these boundaries also reflect contrasting roles contextual considerations may play. Conventional meaning, just as Kaplanian character, is context-independent: for instance, it is in virtue of its fixed conventional profile that an indexical such as ' $\mathrm{I}$ ' manages to refer to alternative individuals on alternative occasions (Recanati 2004, p. 5). Note incidentally that the stress on contextindependence indirectly indicates that the notion of meaning under discussion presupposes certain meaning-independent decisions with respect to the interpretation of actual utterances. For instance, in the sense relevant here, it is not the case that the English expression 'bank' is endowed of a contextually-sensitive meaning - roughly, a metacharacter sensitive to conversational interests, and able to yield either the constant function leading to financial institutions, or the different constant function associated with the sides of a river. ${ }^{3}$ Rather, what is under discussion here is 'sentence meaning' only under a technical and theory-laden sense of 'sentence': what is ultimately endowed of (context-independent) meanings are not English expressions at all, but their representatives within a regimented language suitable for the purposes of content determination.

${ }^{3}$ I borrow the notion of a metacharacter from Smith 1989. 
At the other extreme of the divide are uncontroversially contextually impregnated notions, in principle sensitive to any parameter common sense may deem to be of relevance: that Recanati's utterance conveys that he is a good cook depends upon extra-linguistic facts such as the conversants' interests of culinary matters or certain stereotypes on Frenchmen's interest in food. The logical space within which the idea of WIS may thus be allowed to roam may at least in part be characterized by different degrees of contextual dependence, ranging from conventional meaning's insensitivity to pragmatic impartation's promiscuity.

For Recanati, the conceptual schema sketched thus far serves the purpose of introducing and evaluating alternative views of WIS, one relatively close to the contextually indifferent extreme, the other more sympathetically oriented to pervasive contextual intrusions. Since the latter orientation is the one Recanati favors, at least in most of Literal Meaning's chapters, it must be the case that the conceptual framework summarized thus far provides a common ground for the confrontation of the proposals under discussion, in particular the allegedly widespread minimalist attitude on the one hand, and Recanati's own version of Contextualism on the other. In this sense, for minimalists and contextualists alike, conventional meaning plays a certain role, determinant for the establishment of certain independent levels, including the level of WIS, which in turn bear the responsibility for the production of further effects, possibly understandable in terms of pragmatically imparted information content. Thus, contextual influences uncontroversially enter the picture at a level preliminary to the identification of an input for the procedures under analysis — say, a (presumably highly context sensitive) level involving structural and lexical disambiguation, ellipsis, and the like. Furthermore, they play a meaning-controlled role at some intermediary level, in the narrow sense of contextuality constrained by matters of indexicality. Finally, they account for the establishment of the conversational content eventually imparted, on the basis of processes such as Gricean implicatures.

Against this non-inconsiderable amount of (genuine, or for the argument's sake) agreement, the point of contention in Literal Meaning has to do with the structure, composition, and, in particular, contextual sensitivity of the levels intervening between meaning and communication, with a particular focus on WIS. It is to Recanati's treatment of these issues that I now turn. 


\section{The Incomplete}

The gap between conventional meaning and imparted content leaves room for a variety of importantly distinct notions, including (but not limited to) the sort of information relevant for the establishment of logical relations between expressions, conclusions of truthconditions, and the variety of questions that may fall under the heading of 'propositional content'. 4 The question of propositionality seems prominent in Recanati's account: the idea of 'what is said' is immediately clarified in terms of the locution 'the proposition expressed' (Recanati 2004, p. 5). More precisely, Recanati's example seems to indicate that WIS is to be understood along the lines of Kaplan-style content, in the technical sense of "Demonstratives": in different contexts the sentence 'I am French' (or, more appropriately, a disambiguated representation of it) expresses different 'contextdependent propositions', depending on who is speaking. Unfortunately, this indirect indication of the sense in which 'proposition' is to be interpreted, and, as a consequence, the way in which WIS is to be understood, are non-univocal: within the Kaplan-derived traditions, 'content' is itself an importantly underdetermined label, referring sometimes to functions from circumstances to extensions, sometimes to certain complex structured constructions, and at other times to informational units. ${ }^{5}$ The only additional indication provided in the initial sections of Literal Meaning is equally unhelpful: a complete proposition, so we read, is "something truth-evaluable" (Recanati 2004, p. 6). How 'truth-evaluable' is to be interpreted remains however unclear: so-called propositional functions, for instance, are surely truth-evaluable (with respect to appropriate parameters), but do not seem to fit Recanati's idea of what is at issue at the level of WIS.

It is precisely this initially slightly off-focus idea of a complete proposition that seems to guide the discussion in chapter one, and later in chapter four of Literal Meaning. Were the notion of completeness presented with clarity, the idea of WIS would become more narrowly constrained: not only 'from below', as (at least partially) determined by conventional meaning, and 'from above', as (at least partially) determining what is implicated, but also "from the outside', as something obeying the additional requirement of completeness. Yet, an important glimpse into Recanati's ideas on this theme

\footnotetext{
${ }^{4}$ For independent considerations stressing the differences between these levels, see Predelli 2005.

${ }^{5}$ Compare in particular the "philosophical" commentaries in Kaplan's "Demonstratives" and "Afterthoughts" with the structure of its formal apparatus.
} 
emerges from his presentation of the conception of WIS he regards as opposite to his own, Minimalism.

What I call 'Minimalism' construes the constraint very strictly: 'what is said', in the minimalist framework, departs from the conventional meaning of the sentence (and incorporates contextual elements) only when this is necessary to 'complete' the meaning of the sentence and make it propositional. (Recanati 2004, p. 7)

One idea that apparently plays a role here is the familiar notion of meaning-controlled contextuality: for a minimalist, the level of WIS is determined on the basis of literal meaning, flanked by contextual considerations (i.e., 'departures' from meaning) only to the extent to which literal meaning itself is sensitive to the identity of this or that contextual parameter. The WIS for 'I am French', for instance, depends upon who is speaking precisely because the conventional meaning of ' $\mathrm{I}$ ' manages to secure a reference only on the basis of the selection of an appropriate agent.

It is true that Recanati's minimalists are willing to incorporate in their account 'unarticulated' constituents, but only in what must surely be a scare-quote sense of underarticulation. So, for a minimalist, a constituent is needed to obtain the WIS for, say, an utterance of 'I noticed', but only because the predicate "notice' "arguably denotes a two-place relation" (Recanati 2004, p. 7, n. 2). In this sense, even though only one slot for the relation at issue is filled by the contribution provided by an overt lexical item, another constituent must be provided in order to 'complete' the desired WIS. Thus, what Recanati concedes to the minimalists is only a very watered-down sense of 'underarticulation', the strong sense of 'underarticulation' being one of the trademarks of Recanati's own version of Contextualism. As hinted above, for Recanati, and for anybody else, the item to which considerations of context-independent meaning may apply are not surface structures but regimented affairs, and at this level, at least according to a natural understanding, the request for the object being noticed is apparently very much articulated and meaning-controlled.

These hints seem to indicate that the distinctive feature of the minimalist account of WIS is its restriction of the relevant contextual matters to meaning-controlled contextuality. Completeness, in this sense, would at best be the result of whatever regularity happens to be encoded within the meaning of this or that English expression. If, on the one hand, what meaning happens to demand results in less than full fledged, complete propositions, nothing in the 
meaning-controlled version of Minimalism ought to generate cause for complaint. If, on the other, what meaning requires by far exceeds the minimal requirement for minimal completeness, minimalists of the appropriate ilk may well enjoy their opulent results with no fear of inconsistency.

Still, as stressed by the italicized material in the quote above, it is the red-herring of completeness that apparently governs Recanati's initial arguments against Minimalism. One of the results of the presumed marriage between meaning-controlled contextuality and propositional completeness is the implicit notion that, as long as completeness is not at issue, a minimalist view of meaning is committed to a very restricted account. For instance, Recanati seems to reason that, since (pace Perry) 'it is raining' may occasionally be uttered so as to describe a non-rainless world, a location is not needed for completeness' sake; hence, he concludes, no location may enter WIS according to the meaning-governed procedures to which minimalists are sympathetic. Yet, although minimalists may well embrace this conclusion because of idiosyncratic views on the meaning of it rains', they need not do so. It seems perfectly compatible with the idea that the only form of contextuality relevant at the level of WIS is meaning-controlled that, for instance, some utterances of 'it rains' say that it is raining in Palo Alto.

The converse aspect of the marriage of meaning-control with completeness is the idea that, in the minimalist picture, meaning ought to demand contextual intervention only to some very restricted, completeness-guided extent. In Recanati's account of Minimalism, whenever incompleteness is lurking, meaning ought to restrict its interest in contextual matters only to the most economical (unfortunately in a never rigorously specified sense of economy) items sufficient for propositional completion. For instance,

From a minimalist point of view, [...] 'I've had breakfast' expresses the proposition that $S$ (the speaker) has had breakfast before $t *$ (the time of utterance). [...] This is so because the 'minimal' interpretation, to the effect that the speaker's life was not entirely breakfastless, is sufficient to make the utterance propositional. (Recanati 2004, p. 8)

Yet, it would seem that, even on a minimalist understanding, meaning could do much more than that: some element in 'I've had breakfast' may after all turn out to be indexical in a richer way that that allowed by Recanati. 
Of course, Recanati is entitled to define Minimalism any old way he wishes: if what Recanati's minimalists care about is propositional completeness, my insistence on meaning-controlled contextuality remains idle with respect to their project. But what is at issue here are not arbitrarily defined views: what matters is whether there are important theoretical reasons for being interested on a particular account of the gap separating conventional meaning and communication, and of the degrees of contextuality pertinent to it. As will emerge in the remainder of this essay, the notion of meaninggoverned contextuality has a very important claim to centrality at least for some of the levels traditionally understood as semantic. If Recanati's considerations aim at addressing WIS as a semantic notion (or, at least, if they are concerned with those levels of WIS with semantic relevance), it is the relationships between meaning and context, rather than the mere idea of propositional completeness, that need to be confronted.

\section{The Automatic}

Chapter four deals with one of the worries to which I alluded in section 1: the constraints within which WIS is supposed to be identified are too loose for a profitable discussion of this or that analysis of its exact nature. Indeed, according to what Recanati calls the syncretic view, two different but equally useful conceptions of 'what is said' may be sandwiched between the lower bound provided by contextually insensitive meaning, and the upper bound of wide Gricean pragmatics. For Recanati, however, the syncretic view does not fare any better than standard Minimalism: its minimalist understanding of at least one of the levels in question is grounded on an inadequate literalist picture.

Recanati's description of Literalism is epistemologically oriented: according to a literalist, a process of semantic interpretation may be isolated, which appeals solely to the interpreter's knowledge of the relevant language, in turn understood as a "theory by means of which one can deductively establish [... ] truth-conditions" (Recanati 2004, p. 54). But if the deductive process in question is at all adequate, it must be the case that such truth-conditional conclusions may be drawn by virtue of the features conventionally encoded within the language in question. In this sense, then, Literalism re-proposes the minimalist conception of meaning, truth, and contextuality, at least with respect to a particular level among the candidates for the 
role of WIS: contextuality, of the type relevant here, must be reduced to meaning-controlled contextuality.

The worries I expressed when I discussed Recanati's first chapter seem to be relevant also at this stage. If the role which a so-called 'semantic' level of WIS is supposed to play is unspecified, the adequacy of this or that analysis of it remains unassessable. Worse still, Recanati's continued insistence in chapter four on the criterion of complete propositionality introduced in chapter one is not only seemingly unwarranted, but also presumably idle with respect to his strategy: even assuming that completeness is indeed a desideratum for an adequate notion of WIS, it is not clear that the idea of meaningcontrolled contextuality characteristic of Literalism may not yield the desired results. Recanati is however apparently aware of this latter objection, because he devotes a central section of chapter four to an explanation of why meaning-controlled contextuality, though in abstract apparently able to yield the results on which Recanati insists, is nevertheless independently inadequate.

For Recanati, the inadequacy of the forms of contextuality Literalism may admit does not have to do with its structure, in particular, with the demand that it be meaning-controlled. It has rather to do with its nature:

The hallmark of the more radical form of context-dependence is the fact that any piece of contextual information may be relevant. But the context that comes into play in the semantic interpretation of indexicals is not the total pragmatic context; it is a very limited context which contains only a few aspects of the pragmatic context: who speaks, when, where, and so forth. (Recanati 2004, p. 56)

In fact, even this temporary concession is soon retracted:

Even if we restrict our attention to expressions traditionally classified as indexicals, we see that they involve a good deal of semantic underdeterminacy. This is true, in particular, of demonstratives. [...] We encounter the same sort of problem even with expressions like 'here' and 'now' which are traditionally considered as pure indexicals $[\ldots]$. (Recanati 2004, p. 57)

It follows that, according to Recanati, the problem with the form of contextuality recognized by literalist approaches does not reside in their insistence on meaning-controlled contextuality, but rather in the fact that, regardless of the role meaning plays with 
respect to it, the correct results may be achieved only on the basis of genuinely pragmatic considerations. The point is not that ' $\mathrm{I}$ ', 'this' or even the possessive in 'John's car' are conventionally endowed of non-constant characters. It is rather that, once the procedure demanded by their character is set in motion, the appropriate semantic value may be identified only by taking into consideration the features of the wide context. The literalist picture of an automatic interpretation of context-dependent expressions, so Recanati objects, is inadequate.

This sort of reply may also be applied to my considerations at the end of section 2. That meaning-controlled contextuality may achieve the desired conclusions for 'I've had breakfast' or 'it rains' now counts as a hollow victory for the minimalist/literalist paradigm: regardless of the role conventional meaning manages to play, the intuitively correct propositions may be obtained only on the basis of features of the wide context. What must be at issue, Recanati concludes, is not the automatic form of contextuality literalists are willing to envision, but the uninhibited contextuality eventually appropriate for speaker's meaning.

\section{Semantics, Complete Propositions, and Automatic Interpretation}

According to the foregoing analysis of Recanati's discussion of WIS, the problem with Minimalism/Literalism may be expressed in terms of the uncomfortable conjunction of three aspects: meaning-controlled contextuality, propositional completeness, and automatic saturation. For Recanati, meaning controlled contextuality may arguably achieve the desired results, and yield the desired complete and intuitive propositional contents, but it may do so only by appealing to wide context. On the other hand, complete propositionality may perhaps be achieved on the basis of automatic meaning-controlled processes, but the resulting outcomes would be intuitively inadequate.

The level(s) of WIS under discussion are occasionally labeled by Recanati as levels of semantic propositional content. Insofar as traditional semantic treatments are grounded on a particular view of the relationships between meaning and truth, it would seem that it is the question of meaning-governed contextuality that ought to play a fundamental role. But if issues of saturation are inextricably bound with additional concerns, such as the relationship between narrow and wide context and the automatic conception of character-based contextuality, the target of Recanati's polemics becomes unclear. If, 
in other words, what is being assessed are views such as Minimalism, in which meaning-control is accompanied by additional concerns such as completeness and automaticity, Minimalism's presumed defeat would remain largely irrelevant for the treatment of genuinely semantic questions. On the other hand, if the true target of Recanati's discussion is a semantically relevant level of WIS, that is, the outcome of a semantic procedure of interpretation, it is unclear why the ideas of complete propositionality or automaticity may be relevant.

In particular, the idea of a role for wide context at a level prior to implicatures and pragmatic impartations is not only compatible with customary semantic approaches, but is in fact typically presupposed by it. Traditional philosophy of language relies on the idea of an interpretive system, invariably developed as a function from its input to, say, extensional results. On the assumption that such results ought to be empirically adequate, i.e., that they ought to reflect competent speakers' intuitions, it follows that the input for interpretive systems must be regimented expressions, that is, items resulting from processes such as lexical and structural disambiguation, or ellipsis unpacking. Uncontroversially, these are processes guided by pragmatic considerations in the widest sense of the term, and sensitive to features such as the topic of conversation, the interests of the conversants, or the speaker's intentions. Questions of disambiguation or ellipsis unpacking are of course in themselves tangential to the issues Recanati addresses and, more generally, to the problems pertaining to the identification of WIS. Still, as indicated at the end of section 3, Recanati's consideration converge towards a conclusion about the very nature of contextual intrusions, regardless of the role they may come to play: it is by virtue of their alleged wide-context dependence that phenomena such as indexical saturation are taken as symptomatic of a troublesome tension within Literalism. In the absence of independent arguments to the contrary, however, the sheer non-automatic flavor of the type of saturation required for complete and intuitively adequate propositionality is hardly problematic for the traditional viewpoint.

Of course, all of the above is of relevance only if the idea of meaning-controlled contextuality is indeed the trademark of the traditional approach Recanati aims at attacking. But the insistence on meaning-control is not an accidental philosophical intrusion within the mechanisms responsible for the analysis of the genuinely semantic level sandwiched between conventional meaning and pragmatic impartations. At least on the accepted sense of the term, semantics 
studies logical relations and properties, such as redundancy, synonymy, entailment, and in particular what is commonly called "truth in virtue of meaning', that is, it is responsible for a systematic account of the relationships between meaning and truth. Nothing in Recanati's discussion of wide contextuality appears to have a bearing in this respect.

\section{Conclusion}

The target of Recanati's discussion in Literal Meaning is the idea of WIS. Yet, the logical space flanked by conventional meaning on the one hand, and pragmatic impartations on the other, includes a variety of distinct notions, presumably playing contrasting accounts in a systematic treatment of natural languages and communication. Recanati's discussion of Minimalism and Literalism indirectly provides a more constrained definition of the level of WIS he is after, a level consisting of intuitively appropriate complete propositions, at least partly determined by appeals to wide context. It is not immediately clear from Literal Meaning why this level deserves detailed philosophical analysis. But Recanati's more than occasional insistence on matters of semantics seems to motivate the only answer I can venture on his behalf: what is at issue is a semantic conception of WIS, that is, the sort of questions commonly treated by customary interpretive systems. If this reply were correct, then the presumed failure of Minimalism and Literalism would be of undeniable philosophical relevance: our traditional approach to matters of semantics, so we would be forced to admit, rests on shaky foundations.

But the suggestion that what is at issue is a semantic conception of WIS requires an independent assessment of the criteria Recanati employs in his critical discussion. In particular, the semantic level of inquiry occupies a rather well defined niche within the regularities connecting conventional meaning to results of truth-conditions, propositionality, and eventually communicated content. At this level, it is the notion of what is commonly called truth in virtue of meaning that occupies a central role: semantic interpretive systems lead to results of logical relations on the basis of the truth-related results they establish across the relevant parameters of evaluation. It is an immediate consequence of this sort of concern that the idea of meaning-governed contextuality ought to be the focus of metasemantic queries: questions of propositional completeness or of automatic saturation apparently remain external to the system's mechanisms. 
That this much results from a widely recognized, common understanding of the aims and scope of semantics does not entail that it reflects a sacrosanct and unquestionable understanding of that with which this sort of inquiry ought to be concerned. But the study of levels of WIS distinct from the analysis of the relationships between meaning and truth ought to be motivated by independent considerations, and by arguments supporting its philosophical relevance. It is with respect to these considerations and arguments that the reader of Literal Meaning may be left asking for more.

\section{REFERENCES}

Almong, Joseph, John Perry and Howard Wettstein (eds.), 1989, Themes from Kaplan, Oxford University Press, New York.

Grice, Paul, 1989, Studies in the Way of Words, Harvard University Press, Cambridge, Mass.

Kaplan, David, 1989a, "Demostratives", in Almong, Perry and Wettstein 1989, pp. 481-563.

—, 1989b, "Afterthoughts", in Almong, Perry and Wettstein 1989, pp. 565-614.

Predelli, Stefano, 2005, Contexts: Meaning, Truth, and the Use of Language, Oxford University Press, Oxford.

Recanati, François, 2004, Literal Meaning, Cambridge University Press, Cambridge.

Smith, Quentin, 1989, “The Multiple Uses of Indexicals”, Synthese, vol. 78, pp. 167-191.

Received: May 15, 2005; accepted: September 7, 2005. 